\title{
EVALUATION AND MODELLING THE MICRO-BIOCLIMATOLOGICAL CONDITIONS OF A POPULAR PLAYGROUND IN SZEGED, HUNGARY
}

\author{
L. A. ÉGERHÁZI a , N. KÁNTOR, T. GÁL \\ Department of Climatology and Landscape Ecology, University of Szeged, Szeged, Hungary \\ ${ }^{a}$ E-mail: egerhazil@geo.u-szeged.hu
}

\begin{abstract}
This paper presents a thermal comfort study of a popular playground in Szeged, Hungary in order to find its optimal land cover and vegetation options. For this assessment simulated micro- and bioclimatological conditions recorded on a typical summer day (12th July 2011) were analysed. The thermal and radiation features of the study area were quantified by two biometeorological indices, Predicted Mean Vote (PMV) and Mean Radiant Temperature $\left(T_{\mathrm{mrt}}\right)$. For the simulation of the meteorological parameters and the bioclimate indices, ENVI-met microclimate model was used. The results confirmed that the modelled areas with different land cover provide a variety of thermal conditions for the visitors; moreover, human thermal sensation was significantly affected by the change of the radiation environment.
\end{abstract}

Keywords: thermal effect, urban playground, land cover, numerical simulation

\section{Introduction}

In urban areas the climatological and bioclimatological conditions are modified compared to the rural areas (Unger, 1999), and even inside a city in micro scale these conditions change rapidly following the urban surface characteristics. The setup of the urban surface characteristics is related with the work of planners, architects and urban planners therefore they have an influence on the local and micro-scale climate conditions. The urban planning and planning of urban green spaces is a very complex process and it has several climatological aspects. The final shape of an urban park is designed by the aspects of the architecture but this final setup determines the microclimate of that area and finally the thermal comfort of the visitors. As a result of the thermal comfort conditions, the visitors or users of the urban park may alter their opinion about it. If the park is perfect in architecture aspect, but there is heat stress in most of the time, than the visitors will avoid this area.

Fortunately, in the last decades there have been numerous researches in the topic of microclimate and thermal comfort, therefore now several methods and software are available to predict the microclimate conditions of an urban park when it exists only in plans, or before the construction begins (e.g. Lahme and Bruse, 2003; Gulyás et al., 2006; Chow et al., 2011; Fröhlich and Matzarakis, 2012). This study is an example for this micro-scale modeling methods, which can give useful information for the architects to make sure that the finally constructed open space or park has the optimal or best setup in several aspects.

\section{Study area and applied methods}

\subsection{Study area}

Our thermal comfort examinations took place in the centre of Szeged, located in the south-eastern part of a Central-European state, Hungary $\left(46^{\circ} \mathrm{N}, 20^{\circ} \mathrm{E}\right)$. The investigated approximately $3300 \mathrm{~m}^{2}$ large area is one of the most modern and well-attended playground in the city. In this open space children can choose among several toys, jungle gyms as well as swings, and 20 benches offer seating place for the visitors. In the western part of the playground, a cottage is situated where the visitors can play even in bad weather.

The surface of the area is primarily covered by light-coloured paving stone that protects the playing children from greater injuries. Different land cover can only be found on two parts of the playground: the children's sand pits are filled with sand, and the immediate vicinity of the cottage and the southwester corner of the playground is paved. The vegetation is considerable (primarily deciduous trees), however, they are 

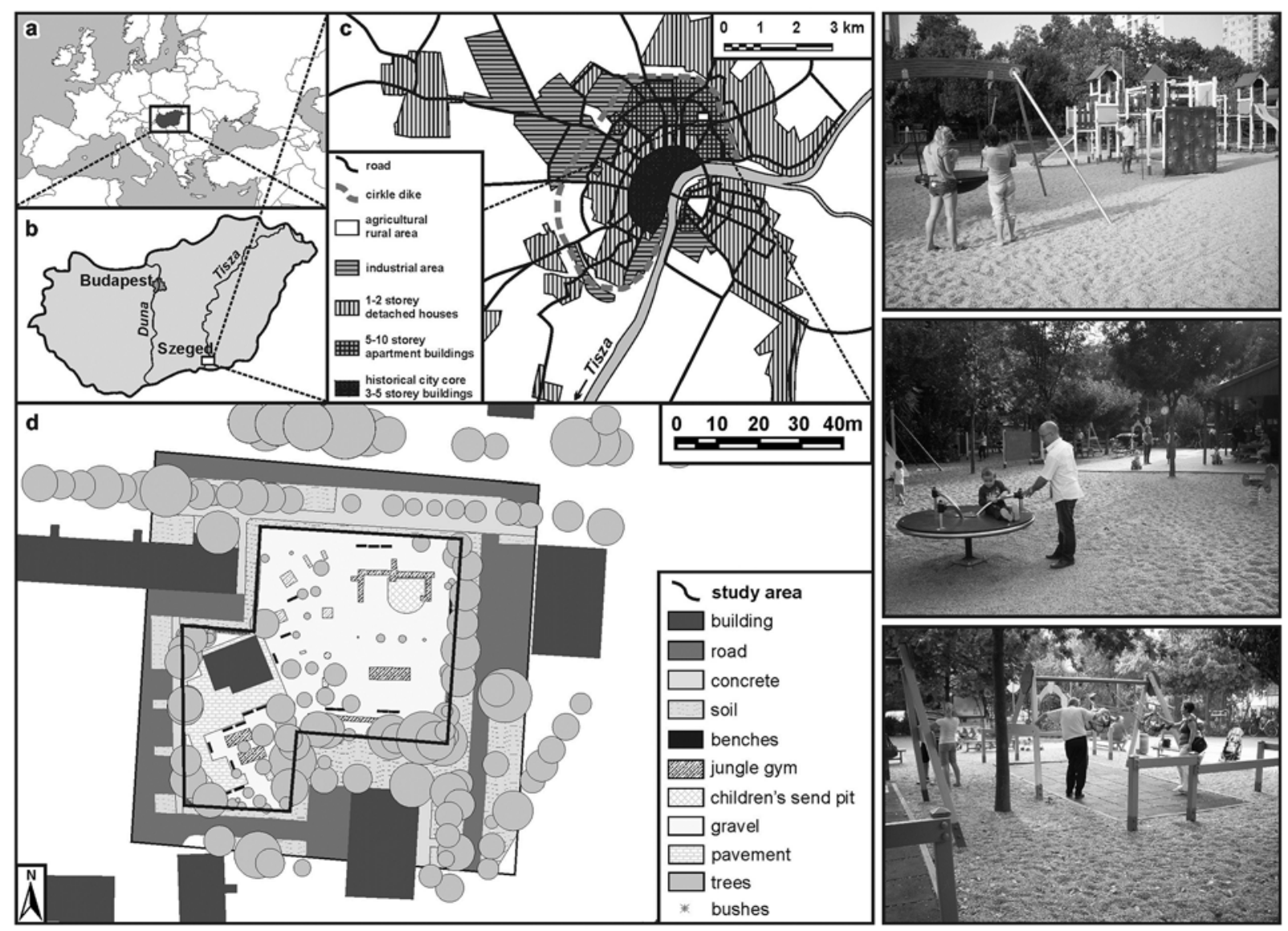

Fig. 1. Geographical location of the study area and some photographs from the investigated playground

mainly located in the border regions of the study area. Therefore during forenoon and in the early afternoon hours, a large part of the playground is exposed to the sunlight (Fig. 1).

\subsection{Methods - simulation with ENVI-met}

ENVI-met is a three-dimensional non-hydrostatic climate model, which is able to model the interactions in the surfaces-atmosphere-vegetation system with relatively high temporal (10 min) and spatial (0.5-10 m) resolution (Bruse and Fleer, 1998). The simulation required two groups of input data: the configuration file (.cf) contains the basic settings and the necessary meteorological parameters of the simulation while the area input file (.in) includes the morphological elements (buildings, plants, land covers etc.) of the investigated area.

The present study introduces the use of ENVI-met in the comparison of the effects of different land covers and designs on the micro- and bioclimatological conditions. This latter was quantified by two thermal indices beside air temperature: Mean Radiant Temperature $\left(T_{\text {mrt }}\right)$ describes the radiation environment of an area, while Predicted Mean Vote (PMV) quantifies the thermal sensation of the people.
The simulation was run on a typical hot, cloudless summer day (12. 07. 2011), because at this period the differences in the thermal and microclimatic environment can clearly be observed. As parameters of the modelling procedure, 18 hours (00:00-18:00) of total simulation time and a spatial resolution of $1.5 \mathrm{~m}$ was adjusted in ENVI-met. The simulation results regarded to the bioclimatological references height of $1.1 \mathrm{~m}$. Table 1 shows the basic settings of the simulation and the necessary meteorological data obtained from the meteorological station of the Hungarian Meteorologi-

Table 1. The basic settings of the simulation

\begin{tabular}{ll}
\hline Wind speed in $10 \mathrm{~m}[\mathrm{~m} / \mathrm{s}]$ & 3.4 \\
Wind direction $\left[^{\circ}\right]$ & 325 \\
Temperature $[\mathrm{K}]$ & 296 \\
Relative humidity in $2 \mathrm{~m}[\%]$ & 58 \\
Spec. humidity in $2500 \mathrm{~m}[\mathrm{~g} / \mathrm{kg}]$ & 7 \\
Roughness & 0.1 \\
Total simulation time $[\mathrm{h}]$ & 18 \\
Start simulation & $00: 00: 00$ \\
\hline
\end{tabular}




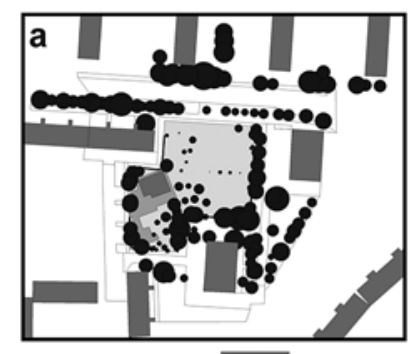

Building

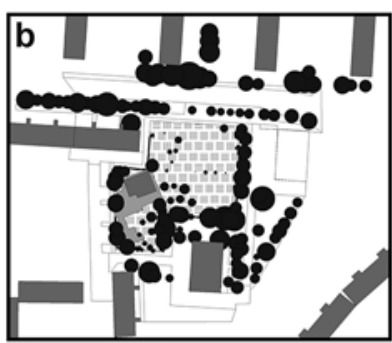

Trees
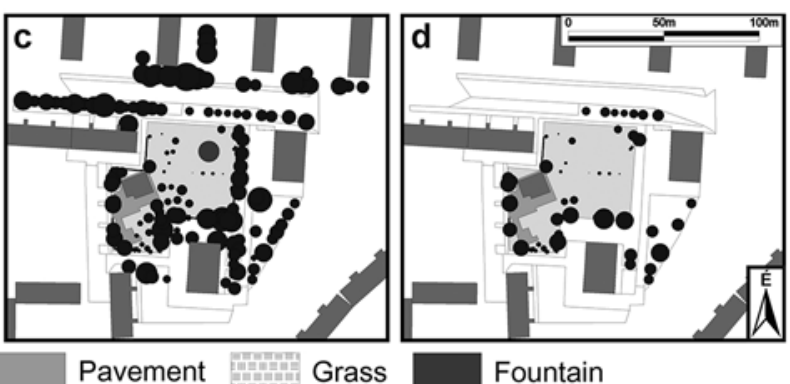

Fig. 2. The schematic pictures of the four simulation scenarios

cal Service situated in the city centre of Szeged (Unger and Gál, 2011).

Four simulation scenarios were created in ENVImet to find the optimal land covers and design for the studied playground. Scenario 1 contains the base area without any modification (Fig. 2a). In scenario 2, grassy land cover was employed instead of gravel (Fig. 2b). In case of the scenario 3, a little fountain (lake) was virtually built in the north-eastern part of the playground, but the original land covers were retained (Fig. 2c). Finally, in scenario 4, a part of the vegetation was removed (Fig. 2d). This paper demonstrates the results of these modifications at a typical time (11 a.m.) on the investigated simulation day.

\section{Results}

\subsection{Thermal and radiation features of the playground}

In the first part of the analysis, the results of scenario 1 were examined. Figure 3a shows that the spatial patterns of the simulated air temperature was relatively homogeneous, differences were not larger than a few tenths of degree Celsius all over the area. Warmer air temperature values (about $24^{\circ} \mathrm{C}$ ) occurred in the northern areas. In the eastern and southern parts, where the vegetation is significant, the temperature was slightly cooler (about $23.4-23.6^{\circ} \mathrm{C}$ ).
However, the maps of $T_{\text {mrt }}$ and PMV (Fig. 3b and 3c) representing the spatial distribution of the radiation environment and the thermal sensation were much diverse, proving the complexity of these bioclimatological indices compared to air temperature. At the same time, these above-mentioned maps illustrate the effects of the different land covers and vegetation types in micro- and bioclimatological sense. The spatial distributions of $T_{\mathrm{mrt}}$ and PMV values were analogous, which supported the fact that the radiation factor plays an important role in human thermal sensation.

Due to the strong direct radiation in this period as well as the significant reflected radiation from the surface of the pavement, the highest $T_{\text {mrt }}$ values $\left(60{ }^{\circ} \mathrm{C}\right)$ occurred in the vicinity of the cottage. In the middle parts of the area, $T_{\text {mrt }}$ values were slightly decreased (50-52 ${ }^{\circ} \mathrm{C}$ ), however significant drop in the values can only be found in the shadow of the trees $\left(38^{\circ} \mathrm{C}\right)$. The heat stress map (PMV map) illustrates that the most unpleasant part (PMV = 1.5, slightly warm - warm thermal sensation) of the playground is situated on the pavement due to the above-mentioned increased radiation. However, under the trees where the incoming and reflected radiation fluxes were both minimal in this period, the thermal conditions were more comfortable and the values approached to $\mathrm{PMV}=0$ (neutral thermal sensation) and the PMV $=-1$ (slightly cool thermal sensation).
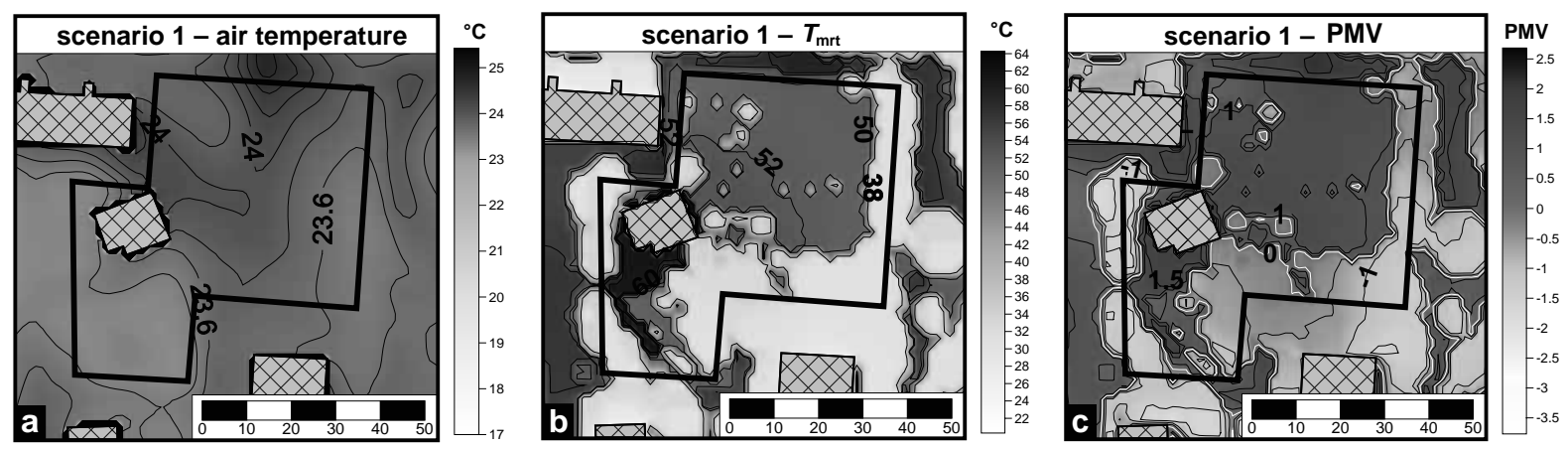

Fig. 3. The thermal features of the study area without modification (scenario 1) 

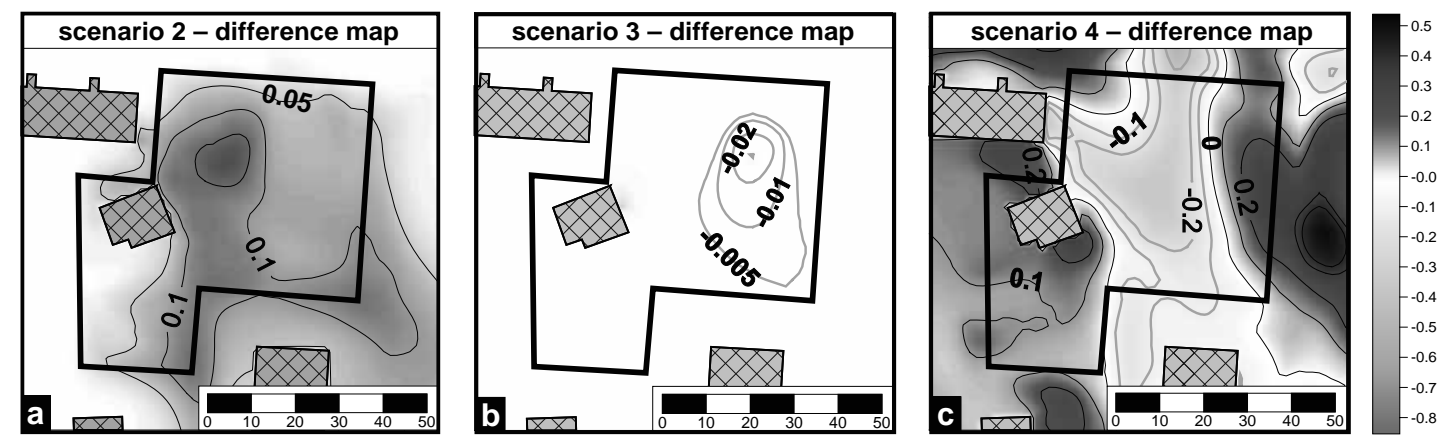

Fig. 4. Differences maps of the modelled air temperature in case of the scenarios (black isolines mark the positive, grey isolines the negative changes)

\subsection{The effects of area modification on the thermal conditions}

In order to compare the scenarios, difference maps were created. In these maps the modelled values of the base area without modification (Fig. 3) were subtracted from the appropriate values of the given scenario (scenarios 2-4), thereby the effects of the modification can easier be observed.

According to Fig. 4a, the air temperature slightly increased in scenario 2 (grassy surface instead of gravel), which can be explained by the different water-holding capacity of the gravel and the grass. However, this difference did not exceed $0.15^{\circ} \mathrm{C}$ anywhere, consequently the influence of the modifications in sce- nario 2 were practically negligible. Similar tendency can be observed in case of the scenario 3 (simulation with fountain): although the air temperature decreased in the vicinity of the fountain, its cooling effect was negligible (Fig. 4b). This can be caused by the fact that the simulation applies simplifications: the fountain was visualized as a small water surface causing reduced cooling effect as that of a sprayed mass of water. Beside this fact, the present version of ENVI-met may not be able to render such fine adjustments employed in scenarios 2 and 3 . On the map of scenario 4 (simulation with reduced vegetation), differential air temperature values varied between -0.2 and $0.2{ }^{\circ} \mathrm{C}$ (Fig. 4c). Positive differences, i.e. increase of air temperature mainly occurs in the border regions of the
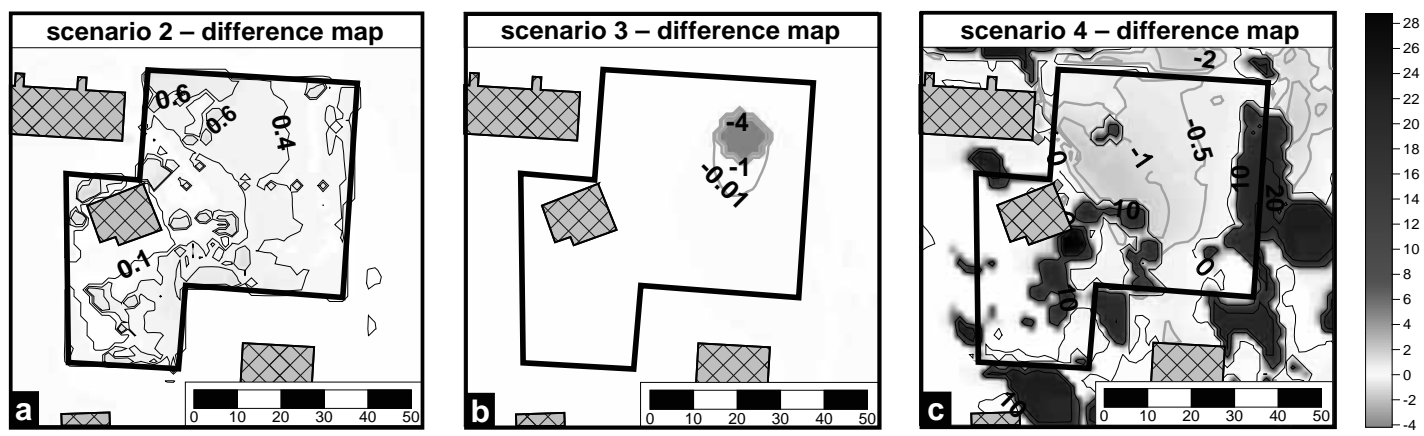

Fig. 5. Differences maps of the modelled $T_{\text {mrt }}$ in case of the scenarios
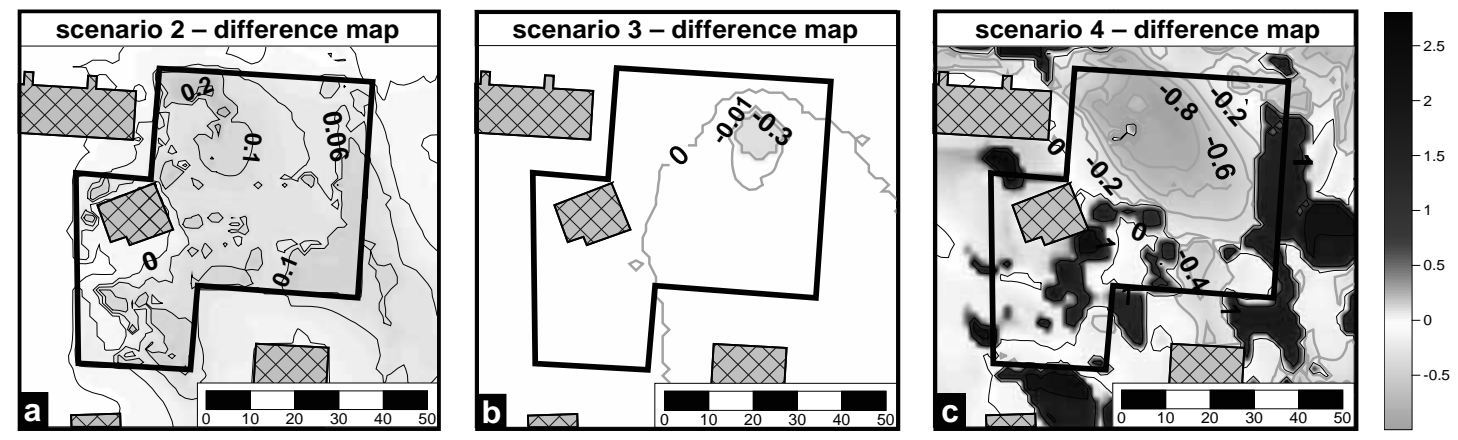

Fig. 6. Differences maps of the modelled PMV in case of the scenarios 
study area, where a part of the vegetation was ignored. In the north-western part of the simulation area, a large group of trees was removed (Fig. 2d), which gave way to the prevailing, north-westerly winds (Table 1 ). The incoming wind cooled down the environment, therefore the temperature in the middle part of the area slightly decreased.

As illustrated in Fig. 5, the variation in the thermal radiation conditions was hardy significant on the first two difference maps (scenarios 2 and 3). In case of scenario 2, the deviations of the $T_{\mathrm{mrt}}$ values not even achieved $1{ }^{\circ} \mathrm{C}$ (Fig. 5a). In scenario 3, the effect of the fountain was limited and extended only the area of the water surface (Fig, 5b).

However, map of scenario 4 highlighted that the modification of the vegetation caused significant changes in the radiation environment (Fig. 5c). The dark blots in the map indicated places of removed vegetation, where the increase of $T_{\text {mrt }}$ values exceeded even $20^{\circ} \mathrm{C}$ due to the strong incoming radiation.

Although the air temperature and $T_{\text {mrt }}$ values are important indicators of thermal comfort, PMV can predict and quantify how people sense the thermal conditions of a given area. Therefore, the analysis of the spatial patterns of the PMV values was explicitly pronounced in of the investigated scenarios. Figure 6 shows the difference maps of the modelled PMV values. According to our simulation results, scenarios 2 and 3 caused negligible changes in the thermal environment (Fig. 6a and 6b). The slight increase of PMV values (0.06-0.2 PMV) in scenario 2 and the reduction of that $(-0.01 \div-0.3 \mathrm{PMV})$ in the vicinity of the fountain (scenario 3) were almost imperceptible to human organism. However, the difference map of scenario 4 shed light on the important role of vegetation in thermal comfort investigation (Fig. 6c). Namely, the removal of trees from certain parts of the playground caused an increase of as much as $1 \mathrm{PMV}$, so these areas shifted into another, warmer thermal sensation category (slightly warm instead of neutral). In the middle part of the playground, slightly cooler PMV values $(-0.2 \div-0.8)$ can be found due to the above-mentioned incoming north-western wind. Consequently, in some cases the position of the trees may contribute to the ventilation of the area providing more comfortable environment.

\section{Conclusions}

Some introductory results of a thermal comfort investigation based on the simulation of micro- and bio- climatological conditions were presented discussing the effect of different land covers on the thermal comfort sensation. Four simulation scenarios were carried out by the model ENVI-met, where the thermal environment was characterized by bioclimatic indices $T_{\mathrm{mrt}}$ and PMV beside air temperature.

The obtained results show that a grassy land cover (scenario 2) and a virtual fountain (scenario 3) caused only slight variations in the thermal condition. Contrary to the expected results, the influence of these two scenarios was not significant according to the simulation. This can probably be explained by the fact that it is difficult to treat these minor changes in the model area by the present version of the simulation. However, the outcome of scenario 4 revealed the importance of the vegetation in the thermal sensation. The reduction of the number of trees increased the thermal load in the playground. At the same time, an increased ventilation on the area occurred by the prevailing wind.

The aim of this study to emphasize the importance of modelling procedure in the process of urban planning and to give a hand in the development of a comfortable urban environment.

\section{References}

Bruse, M., Fleer, H. (1998), Simulating Surface-Plant-Air Interaction Inside Urban Environments with a Three Dimensional Numerical Model. Environmental Softwere and Modelling, 13, 373-384.

Chow, W. T. L., Pope, R. L., Martin, C. A., Brazel, A. J. (2011), Observing and modeling the nocturnal park cool island of an arid city: horizontal and vertical impacts. Theor Appl Climatol, 103, 197-211.

Fröhlich, D., Matzarakis, A. (2012), Modeling of changes in thermal bioclimate: examples based on urban spaces in Freiburg, Germany. Theor Appl Climatol, DOI: 10.1007/ s00704-012-0678-y.

Gulyás, Á., Unger, J., Matzarakis, A. (2006), Assessment of the microclimatic and human comfort conditions in a complex urban environment: Modelling and measurements. Building and Environment, 41, 1713-1722.

Lahme, E., Bruse, M. (2003), Microclimatic effects of a small urban park in densely built-up areas: Measurements and model simulations. ICUC5, Lodz, 1-5 September 2003, p. 4.

Unger, J. (1999), Comparisons of urban and rural bioclimatological conditions in the case of a Central-European city. International Journal of Biometeorology, 43, 139-144.

Unger, J., Gál, T. (2011), Automata állomáspár Szegeden A városi klímamódosító hatás online megjelenítése [Automatic station pairs in Szeged - The online visualization of the climate modification effect of the city (in Hungarian)], Légkör, 56, 93-96. 